\title{
Uterine compression sutures for management of severe postpartum haemorrhage: five-year audit
}

\author{
Victoria YK Chai, William WK To *
}

This article was published on 21 Oct 2013 at www.hkmj.org.

\section{A B S T R A C T}

Objectives: To audit the use of compression sutures for the management of massive postpartum haemorrhage and compare outcomes to those documented in the literature.

Design: Retrospective study.

Setting: A regional obstetric unit in Hong Kong.

Patients: Patients with severe postpartum haemorrhage encountered over a 5-year period from January 2008 to December 2012, in which compression sutures were used for management.

Main outcome measures: Successful management with prevention of hysterectomy.

Results: In all, 35 patients with massive postpartum haemorrhage with failed medical treatment, for whom compression sutures were used in the management, were identified. The overall success rate for the use of B-Lynch compression sutures alone to prevent hysterectomy was $23 / 35$ (66\%), and the success rate of compression sutures in conjunction with other surgical procedures was 26/35 (74\%). This reported success rate appeared lower than that reported in the literature.

Conclusion: Uterine compression was an effective method for the management of massive postpartum haemorrhage in approximately $70 \%$ of cases, and could be used in conjunction with other interventions to increase its success rate in terms of avoiding hysterectomy.

Hong Kong Med J 2014;20:113-20

DOI: 10.12809/hkmj134023

VYK Chai, MB, BS, MRCOG

WWK To *, MD, FRCOG

Department of Obstetrics and Gynaecology, United Christian Hospital, Kwun Tong, Hong Kong

* Corresponding author: towkw@ha.org.hk

New knowledge added by this study

- Compression sutures are effective in the management of postpartum haemorrhage arising from uterine atony as well as placenta praevia.

- In an unselected case series audit in a regional obstetric training unit, the efficacy of uterine compression sutures appeared to be lower than that reported in the literature.

Implications for clinical practice or policy

- Uterine compression sutures should be adopted as part of the management of severe postpartum haemorrhage in local obstetric units. Contingent treatment protocols for further interventions should be available if compression sutures fail.

\section{Introduction}

Postpartum haemorrhage ( $\mathrm{PPH})$ is a serious and life-threatening obstetric complication. It is usually defined as an estimated blood loss of more than $500 \mathrm{~mL}$ after delivery and occurs in around $5 \%$ of all deliveries. ${ }^{1}$ As increased maternal morbidity and morbidity are associated with further blood loss, alternative definitions for severe $\mathrm{PPH}$, such as estimated blood loss exceeding 1000 $\mathrm{mL}$, are commonly used in various guidelines. ${ }^{2}$ Conventionally, the first-line treatment options for PPH include conservative management with uterotonic drugs (oxytocin or prostaglandins), while second-line therapy includes uterine packing, external compression with uterine sutures, selective devascularisation by ligation, or embolisation of the uterine artery.-7 These various treatment modalities have been included as an integral part of the HEMOSTASIS management algorithm widely advocated in the UK. ${ }^{8}$ The use of such measures should reduce the need for hysterectomy, which is associated with further blood loss and additional morbidity. ${ }^{9}$

The B-Lynch suture has been the most wellestablished compression suture technique since reporting of the first published series in 1997, and described oversewing of the uterus with a continuous suture to apply ongoing compression. ${ }^{4}$ Since then, the technique has been adopted for control of bleeding in severe PPH due to uterine atony as well as placenta praevia/accreta. ${ }^{10,11}$ Modifications of the original technique, as well as various other suturing 


\section{子宮壓縮縫合術治療嚴重產後出血： 五年醫療紀錄的審計 \\ 蔡汝嘉、杜榮基}

目的：為產後大量出血而須接受子宮壓縮縫合術的病例進行審計, 並 把結果與文獻中所記載的作一比較。

設計：回顧研究。

安排：香港一所分區醫院的產科部門。

患者：2008年1月至 2012 年 12 月的 5 年間, 因產後大量出血而須接受 子宮壓縮缝合術的病人。

主要結果測量：母須作子宮切除而成功治療產後大量出血。

結果 : 研究期間出現產後大量出血但藥物治療未見成效, 最終使用壓 迫縫合術的有35例。單獨使用B-Lynch壓縮縫合以防止子宮切除的病

例有 23 個, 成功率為 $66 \%$ 。須以壓縮縫合配合其他外科手術的成功病 例有 26 個, 成功率為 $74 \%$ 。此成功率似乎低於文獻記載。

結論：約有 $70 \%$ 的病例能以子宮壓縮縫合術成功治療產後大量出血。 子宮壓縮縫合術可配合使用其他外科手術來提高其成功率, 避免子宮 切除。 in detail for the mode of delivery, intrapartum complications, cause of the $\mathrm{PPH}$, sequence of treatment modalities used, estimated total blood loss, any complications resulting from the different manoeuvres, and clinical outcome.

The application of the B-Lynch suture was in accordance with the original description with the hysterectomy wound still open, using either Monocryl or Vicryl No.1 sutures in accordance with the surgeon's preference. In some cases, two separate sutures were applied instead of one continuous suture as described by Bhal et al. ${ }^{15}$ All patients had an indwelling Foley catheter to monitor urine output, and broad-spectrum antibiotics were used for prophylaxis. All patients who had severe haemorrhage treated by intra-operative transfusions and all who had evidence of coagulopathy were admitted to the intensive care unit after their operation.

\section{Results}

There were a total of 26029 deliveries over the review period. The point prevalence of primary PPH with estimated blood loss exceeding $500 \mathrm{~mL}$ was $3.2 \%$ $(\mathrm{n}=825)$, and that exceeding $1 \mathrm{~L}$ (severe $\mathrm{PPH})$ was 105/26 029 (0.4\%). Among the latter, 33 had vaginal delivery and 72 caesarean sections; 25 of these patients were managed by medical treatment alone. Regarding the remaining 80 patients with severe $\mathrm{PPH}$, their management is shown in the Figure.

Within this study period, there were 24 peripartum hysterectomies, of which nine involved attempted use of compression sutures and were included in this case series. The other 15 cases included the 10 who had an a priori hysterectomy (6 for placenta praevia/accreta, 4 for intractable uterine atony) without resort to other more conservative procedures, two for uterine atony with failed treatment following radiological uterine arterial embolisation, and three who had hysterectomy when attempted intrauterine balloon tamponade failed to control the bleeding. Cases that did not entail recourse to uterine compression sutures were not analysed any further.

All the identified cases of PPH that involved the use of compression sutures had failed initial medical management with oxytoxics, including bolus syntometrine, syntocinon bolus or infusion, intramuscular carboprost injections, and in nine cases, additional intramyometrial carboprost injections. The most common aetiology of $\mathrm{PPH}$ was uterine atony $(28 / 35)$, followed by major placenta praevia (7/35), and the total estimated intra-operative blood losses of 1000 to $9300 \mathrm{~mL}$. Approximately $80 \%(28 / 35)$ of the patients were deemed to require intra-operative blood product transfusion, and disseminated intravascular coagulopathy was documented in at least $13(37 \%)$ of 


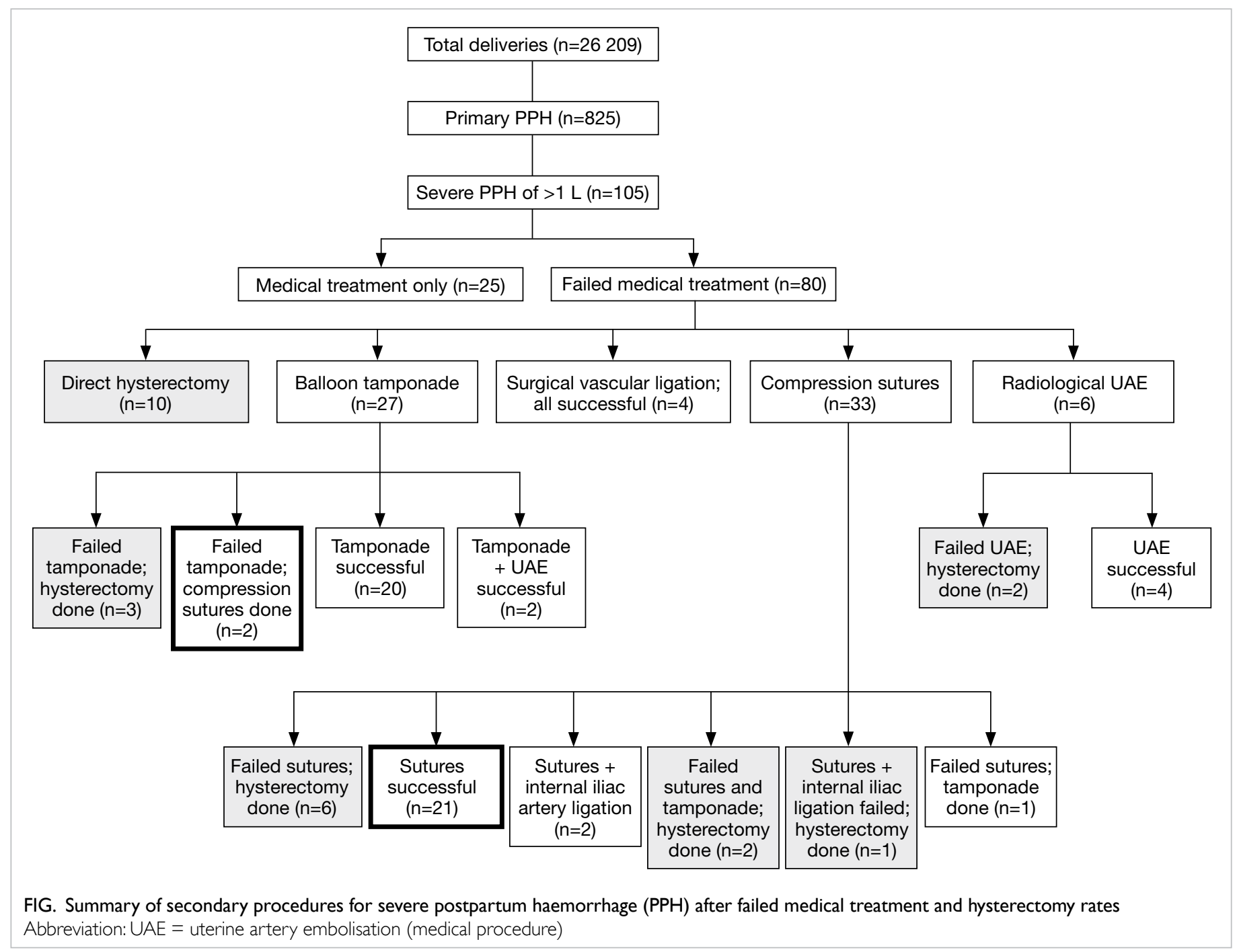

them. In one patient (No. 3), attempted Bhal sutures failed to arrest the bleeding from uterine atony, and subtotal hysterectomy was performed. She had a stump haematoma and massive stump bleeding 3 days later, for which the cervical stump was removed. The bladder was perforated and despite immediate repair at operation, she subsequently developed a vesico-vaginal fistula that was surgically repaired 2 months after the hysterectomy. This was the only patient in our series with major organ trauma. There was no maternal mortality (Table).

One patient (No. 16) had a normal vaginal delivery followed by massive PPH despite oxytoxics. Examination under anaesthesia was performed, and vaginal tears were repaired. Laparotomy and B-Lynch sutures were applied because of concurrent uterine atony, but hysterectomy was finally performed. This patient had the highest estimated blood loss $(9.3 \mathrm{~L})$ in our case series and was the only one given Factor VIIa for coagulopathy management.

Compression sutures were attempted together with intrauterine balloon tamponade in five cases. In one patient (No. 5) with uterine atony after caesarean section for twin pregnancy, abdominal placement of a Bakri balloon (for tamponade) was attempted but failed to arrest the bleeding. The balloon was removed and compression sutures were applied but to no avail, and so a hysterectomy was performed. In another patient with uterine atony following caesarean section for fetal distress (No. 29), when balloon tamponade failed to arrest bleeding, an attempt to add on B-Lynch sutures in the form of a "sandwich"16 led to puncturing of the balloon, and so a hysterectomy was performed. In two others with uterine atony after caesarean section, abdominal placement of a Bakri balloon failed to control bleeding, but a B-Lynch suture was effective (Nos. 25 and 26). In a third patient (No. 27) with major placenta praevia, B-Lynch sutures failed to arrest haemorrhage. The sutures were therefore removed and a Bakri balloon inserted via the hysterotomy wound, and successfully controlled bleeding into the lower uterine placental bed.

In two patients with uterine atony after 
TABLE. Clinical data and variables in patients with use of compression sutures (cases are listed in chronological order)

\begin{tabular}{|c|c|c|c|c|c|c|c|}
\hline $\begin{array}{l}\text { Patient } \\
\text { No. }\end{array}$ & $\begin{array}{l}\text { Age (years) } \\
\text { / parity }\end{array}$ & $\begin{array}{l}\text { Gestation } \\
\text { (weeks) }\end{array}$ & $\begin{array}{l}\text { Mode of } \\
\text { delivery }\end{array}$ & Diagnosis & $\begin{array}{l}\text { Total blood } \\
\text { loss }(\mathrm{mL})\end{array}$ & $\begin{array}{l}\text { Transfusion during } \\
\text { operation (unit) }\end{array}$ & Procedure \\
\hline 1 & 31 / G4P2 & 38 & LSCS & $\begin{array}{l}2 \text { Previous CS } \\
\text { Placenta praevia III }\end{array}$ & 1670 & $2 \mathrm{u} P C$ & $\begin{array}{l}\mathrm{S}+\mathrm{C} \\
\text { B-Lynch }\end{array}$ \\
\hline 2 & 46 / G3P1 & 37 & LSCS & $\begin{array}{l}\text { Fetal distress } \\
\text { APH } \\
\text { Uterine atony }\end{array}$ & 4500 & $\begin{array}{l}6 \text { u PC/WB } \\
4 \text { u FFP } \\
4 \text { u platelets }\end{array}$ & $\begin{array}{l}\text { S + C } \\
\text { B-Lynch } \\
\text { Hysterectomy }\end{array}$ \\
\hline 3 & 38 / G3P2 & 38 & LSCS & $\begin{array}{l}2 \text { Previous CS } \\
\text { Uterine atony }\end{array}$ & $3500+6500$ & $\begin{array}{l}2 \text { u PC/WB + } \\
10 \text { u PC/WB } \\
8 \text { u FFP } \\
8 \text { u platelets }\end{array}$ & $\begin{array}{l}\mathrm{S}+\mathrm{C} ; \text { Bhal } \\
\text { Subtotal hysterectomy } \\
\text { Removal of uterine stump }\end{array}$ \\
\hline 4 & 30 / G1P0 & 38 & LSCS & Placenta praevia III & 1200 & & $\begin{array}{l}S+C \\
\text { B-Lynch }\end{array}$ \\
\hline 5 & 25 / G3P1 & 36 & LSCS & $\begin{array}{l}\text { Twin, APH } \\
\text { Uterine atony }\end{array}$ & 6320 & $\begin{array}{l}7 \text { u PC/WB } \\
8 \text { u platelets } \\
4 \text { u FFP } \\
4 \text { u cryoprecipitate }\end{array}$ & $\begin{array}{l}\mathrm{S}+\mathrm{C} \\
\text { Balloon + B-Lynch } \\
\text { Hysterectomy }\end{array}$ \\
\hline 6 & 40 / G2P0 & 40 & LSCS & $\begin{array}{l}\text { Failed vacuum extraction } \\
\text { Uterine atony }\end{array}$ & 5500 & $\begin{array}{l}8 \text { u PC/WB } \\
8 \text { u platelet } \\
4 \text { u FFP } \\
4 \text { u cryoprecipitate }\end{array}$ & $\begin{array}{l}\text { S + C } \\
\text { B-Lynch } \\
\text { Hysterectomy }\end{array}$ \\
\hline 7 & 32 / G3P1 & 38 & LSCS & $\begin{array}{l}\text { Previous CS } \\
\text { Uterine atony }\end{array}$ & 2000 & 3 u PC & $\begin{array}{l}S+C \\
\text { B-Lynch }\end{array}$ \\
\hline 8 & 31 / G2P0 & 38 & LSCS & Placenta praevia III & 1000 & - & $\begin{array}{l}S+C \\
\text { B-Lynch }\end{array}$ \\
\hline 9 & 41 / G3P1 & 38 & LSCS & $\begin{array}{l}\text { Oblique lie } \\
\text { Placenta praevia III }\end{array}$ & 2562 & $4 u P C$ & $\begin{array}{l}\mathrm{S}+\mathrm{C} \\
\text { B-Lynch }\end{array}$ \\
\hline 10 & 38 / G2P1 & 38 & LSCS & Placenta praevia II & 3500 & $\begin{array}{l}4 \text { u PC } \\
4 \text { u FFP } \\
4 \text { u platelets }\end{array}$ & $\begin{array}{l}S+C \\
\text { B-Lynch }\end{array}$ \\
\hline 11 & 33 / G1P0 & 39 & LSCS & $\begin{array}{l}\text { Prolonged latent phase of } \\
\text { labour; uterine atony }\end{array}$ & 3500 & $\begin{array}{l}4 \text { u PC/WB } \\
4 \text { u FFP }\end{array}$ & $\begin{array}{l}\text { S + C } \\
\text { B-Lynch }\end{array}$ \\
\hline 12 & 32 / G2P0 & 37 & LSCS & $\begin{array}{l}\text { Twin with fetal growth restriction } \\
\text { Uterine atony }\end{array}$ & 1160 & & $\begin{array}{l}S+C \\
\text { B-Lynch }\end{array}$ \\
\hline 13 & 32 / G1P0 & 38 & LSCS & $\begin{array}{l}\text { Fetal distress } \\
\text { Uterine atony }\end{array}$ & 4090 & $\begin{array}{l}8 \text { u PC } \\
6 \text { u FFP } \\
6 \text { u platelets }\end{array}$ & $\begin{array}{l}\mathrm{S}+\mathrm{C} \\
\text { Bhal } \\
\text { Hysterectomy }\end{array}$ \\
\hline 14 & 29 / G1P0 & 38 & LSCS & $\begin{array}{l}\text { Maternal cardiac disease } \\
\text { Uterine atony }\end{array}$ & 3000 & $4 \mathrm{u} P C$ & $\begin{array}{l}S+C \\
\text { B-Lynch } \\
\text { Internal iliac artery ligation }\end{array}$ \\
\hline 15 & 33 / G1P0 & 40 & LSCS & $\begin{array}{l}\text { Failed IOL } \\
\text { Uterine atony }\end{array}$ & 1180 & $2 \mathrm{u} P C$ & $\begin{array}{l}S+C \\
\text { B-Lynch }\end{array}$ \\
\hline 16 & 36 / G2P1 & 40 & SVD & $\begin{array}{l}\text { Uterine atony } \\
\text { Vaginal tear }\end{array}$ & 9300 & $\begin{array}{l}16 \text { u PC } \\
10 \text { u FFP } \\
8 \text { u platelets } \\
\text { Factor VIla }\end{array}$ & $\begin{array}{l}S+C \\
\text { Repair of vaginal tear } \\
\text { B-Lynch } \\
\text { Hysterectomy }\end{array}$ \\
\hline 17 & 22 / G1P0 & 40 & LSCS & $\begin{array}{l}\text { CPD } \\
\text { Uterine atony }\end{array}$ & 1700 & 3 u PC & $\begin{array}{l}\mathrm{S}+\mathrm{C} \\
\text { B-Lynch } \\
\text { Ligation of uterine arteries }\end{array}$ \\
\hline 18 & 27 / G2P0 & 41 & LSCS & $\begin{array}{l}\text { Failed induction of labour } \\
\text { Uterine atony }\end{array}$ & 1200 & - & $\begin{array}{l}\mathrm{S}+\mathrm{C} \\
\text { B-Lynch }\end{array}$ \\
\hline 19 & 37 / G1P0 & 40 & LSCS & $\begin{array}{l}\text { CPD } \\
\text { Uterine atony }\end{array}$ & 1400 & 3 u PC & $\begin{array}{l}S+C \\
\text { B-Lynch }\end{array}$ \\
\hline 20 & 32 / G2P0 & 40 & LSCS & $\begin{array}{l}\text { Prolonged latent phase } \\
\text { Uterine atony }\end{array}$ & 1300 & $2 \mathrm{u} P C$ & $\begin{array}{l}\mathrm{S}+\mathrm{C} \\
\text { B-Lynch }\end{array}$ \\
\hline 21 & 34 / G1P0 & 39 & LSCS & $\begin{array}{l}\text { CPD } \\
\text { Uterine atony }\end{array}$ & 3000 & 4 u PC & $\begin{array}{l}S+C \\
\text { B-Lynch }\end{array}$ \\
\hline 22 & 22 / G1P0 & 41 & LSCS & $\begin{array}{l}\text { Failed IOL } \\
\text { Uterine atony }\end{array}$ & 1700 & $2 u$ PC & $\begin{array}{l}\mathrm{S}+\mathrm{C} \\
\text { Bhal }\end{array}$ \\
\hline
\end{tabular}

Abbreviations: $\mathrm{APH}=$ antepartum haemorrhage; $\mathrm{C}=$ carboprost; $\mathrm{CPD}=$ cephalopelvic disproportion; $\mathrm{CS}=$ caesarean section; FFP = fresh frozen plasma; $\mathrm{IOL}=$ induction of labour; $\mathrm{LSCS}=$ lower-segment caesarean section; $\mathrm{PC}=$ packed cell; $\mathrm{S}=$ syntocinon/syntometrine; $\mathrm{SVD}=$ spontaneous vaginal delivery; $\mathrm{WB}=$ whole blood 
TABLE. (cont'd)

\begin{tabular}{|c|c|c|c|c|c|c|c|}
\hline $\begin{array}{l}\text { Patient } \\
\text { No. }\end{array}$ & $\begin{array}{l}\text { Age (years) } \\
\text { / parity }\end{array}$ & $\begin{array}{l}\text { Gestation } \\
\text { (weeks) }\end{array}$ & $\begin{array}{l}\text { Mode of } \\
\text { delivery }\end{array}$ & Diagnosis & $\begin{array}{l}\text { Total blood } \\
\text { loss }(\mathrm{mL})\end{array}$ & $\begin{array}{l}\text { Transfusion during } \\
\text { operation (unit) }\end{array}$ & Procedure \\
\hline 23 & 29 / G1P0 & 40 & LSCS & $\begin{array}{l}\text { Prolapsed umbilical cord } \\
\text { Uterine atony }\end{array}$ & 1450 & 2 u PC & $\begin{array}{l}\mathrm{S}+\mathrm{C} \\
\text { B-Lynch }\end{array}$ \\
\hline 24 & 31 / G2P0 & 36 & LSCS & Placenta praevia II & 3160 & $\begin{array}{l}4 \text { u PC } \\
4 \text { u FFP }\end{array}$ & $\begin{array}{l}S+C \\
\text { B-Lynch }\end{array}$ \\
\hline 25 & 36 / G1P0 & 38 & LSCS & $\begin{array}{l}\text { Breech } \\
\text { Uterine atony }\end{array}$ & 6030 & $\begin{array}{l}6 \text { u PC } \\
4 \text { u FFP }\end{array}$ & $\begin{array}{l}S+C \\
\text { Balloon failed } \\
\rightarrow \text { B-Lynch }\end{array}$ \\
\hline 26 & 36 / G3P0 & 39 & LSCS & $\begin{array}{l}\text { Prolonged 2nd stage } \\
\text { Uterine atony }\end{array}$ & 3500 & $4 \mathrm{u} P \mathrm{PC}$ & $\begin{array}{l}S+C \\
\text { Balloon failed } \\
\rightarrow \text { B-Lynch }\end{array}$ \\
\hline 27 & 38 / G3P1 & 35 & LSCS & $\begin{array}{l}\text { Placenta praevia IV } \\
\text { Transverse lie }\end{array}$ & 2000 & 3 u PC/WB & $\begin{array}{l}S+C \\
\text { B-Lynch failed } \\
\rightarrow \text { Balloon }\end{array}$ \\
\hline 28 & 35 / G1P0 & 39 & LSCS & $\begin{array}{l}\text { Prolonged 2nd stage } \\
\text { Uterine atony }\end{array}$ & 1000 & & $\begin{array}{l}S+C \\
\text { B-Lynch }\end{array}$ \\
\hline 29 & 28 / G2P0 & 39 & LSCS & $\begin{array}{l}\text { Fetal distress } \\
\text { Uterine atony }\end{array}$ & 5500 & $\begin{array}{l}8 \text { u PC } \\
6 \text { u platelets } \\
6 \text { u FFP }\end{array}$ & $\begin{array}{l}S+C \\
\text { B-Lynch/Bakri failed } \\
\text { Hysterectomy }\end{array}$ \\
\hline 30 & 39 / G2P1 & 39 & LSCS & $\begin{array}{l}\text { Previous CS } \\
\text { Uterine atony }\end{array}$ & 1200 & & $\begin{array}{l}S+C \\
\text { B-Lynch }\end{array}$ \\
\hline 31 & 41 / G3P1 & 37 & LSCS & $\begin{array}{l}\text { Severe pre-eclampsia } \\
\text { Uterine atony }\end{array}$ & 1310 & $2 \mathrm{u} P \mathrm{PC}$ & $\begin{array}{l}S+C \\
\text { B-Lynch }\end{array}$ \\
\hline 32 & 26 / G1P0 & 40 & LSCS & $\begin{array}{l}\text { CPD } \\
\text { Uterine atony }\end{array}$ & 1000 & & $\begin{array}{l}\mathrm{S}+\mathrm{C} \\
\text { Bhal }\end{array}$ \\
\hline 33 & 30 / G2P0 & 40 & LSCS & $\begin{array}{l}\text { Prolonged labour } \\
\text { Uterine atony }\end{array}$ & 2200 & $2 \mathrm{u} P C$ & $\begin{array}{l}\mathrm{S}+\mathrm{C} \\
\text { B-Lynch }\end{array}$ \\
\hline 34 & 31 / G2P1 & 38 & LSCS & $\begin{array}{l}\text { Breech } \\
\text { Uterine atony }\end{array}$ & 5200 & $\begin{array}{l}8 \text { u PC } \\
6 \text { u platelets } \\
6 \text { u FFP }\end{array}$ & $\begin{array}{l}\text { S + C } \\
\text { B-Lynch } \\
\text { Internal iliac artery } \\
\text { ligation; hysterectomy }\end{array}$ \\
\hline 35 & 29 / G1P0 & 38 & LSCS & $\begin{array}{l}\text { Fetal distress } \\
\text { Uterine atony }\end{array}$ & 6800 & $\begin{array}{l}8 \text { u PC } \\
8 \text { u platelets } \\
6 \text { u FFP }\end{array}$ & $\begin{array}{l}\text { S + C } \\
\text { B-Lynch } \\
\text { Hysterectomy }\end{array}$ \\
\hline
\end{tabular}

caesarean section (Nos. 14 and 17), continuous bleeding from the vagina was observed after application of B-Lynch sutures, and thus ligation of the internal iliac arteries/uterine arteries was performed with effective outcome. In a third patient (No. 34), internal iliac artery ligation failed to control the haemorrhage, and so a hysterectomy was performed. Four other patients (Nos. 2, 6, 13, and 35) failed to have their bleeding controlled by compression sutures and underwent hysterectomies.

Thus, in our series the overall success rate of compression sutures alone as the primary secondline $(n=21)$ or rescue procedure $(n=2)$ to prevent hysterectomy was $23 / 35(66 \%)$. The success rate of compression sutures in conjunction with other second-line procedures (two with iliac artery ligation and one with intrauterine balloon tamponade) was 26/35 (74\%). Specifically, when the aetiology of the $\mathrm{PPH}$ was taken into consideration, the success rate for B-Lynch compression sutures in patients with uterine atony was $17 / 28(61 \%)$ and that for placenta praevia cases it was $6 / 7$ (86\%). The Bhal suture was used in four cases only (Nos. 3, 13, 22, and 32) and its success rate of $50 \%$ was not statistically significantly different from that of B-Lynch sutures.

Particular putative patient risk factors that could reliably predict the success of compression sutures as a means of avoiding hysterectomy included age, parity, mode of delivery, operator experience, aetiology of the PPH, and the extent of blood loss at that time. Based on a multivariate stepwise regression analysis, no significant risk factors for the success of compression sutures could be identified in the current data set.

\section{Discussion}

In this series, we were able to avoid hysterectomy with the use of uterine compression sutures, either alone or in combination with other surgical interventions, in only around $70 \%$ of patients with severe $\mathrm{PPH}$. This success rate was lower than that reported in many other reported case series. ${ }^{4,5,11-14,17-21}$ 
The first description of uterine compression sutures was published in 1996 as a single case report from Zurich, ${ }^{22}$ which was followed by the famous report of five consecutive cases utilising the B-Lynch suture in 1997. ${ }^{4}$ Various modifications of the B-Lynch suture, and various other compression suture techniques have been reported since then. In 2000, Cho et $\mathrm{al}^{13}$ described a haemostatic multiple square suture to approximate the anterior and posterior uterine wall. In 2002, Hayman et $\mathrm{al}^{5}$ proposed a uterine compression suture that involved two vertical apposition sutures together with two transverse horizontal cervico-isthmic sutures. In 2005 , Hwu et a $1^{14}$ described the use of two parallel vertical compression sutures placed in the lower segment to control bleeding from placenta praevia. These sutures compressed the anterior and posterior uterine wall without penetrating the full thickness of the posterior wall. Another modification was the Pereira suture reported in 2005, which consisted of longitudinal and transverse sutures applied with superficial intramyometrial bites only. ${ }^{17}$ In the current case series, the only modification to the B-Lynch suture utilised was the Bhal technique. ${ }^{15}$ This entailed two sutures instead of one, with the knots tied in the anterior-inferior margin of the lower uterine segment, without any difference in the compression effects compared to the original B-Lynch suture. It can be seen that the principle, namely, compression of the uterine body, remains basically the same for all types of compression sutures. The main differences being the figure at which the suture is applied, the numbers of longitudinal and/or transverse sutures used, and whether or not the uterine cavity is penetrated. ${ }^{23}$

In the literature, some series have described compression sutures solely used for placenta praevia/accreta, ${ }^{11,14,18,24}$ while others detailed their use exclusively for atonic uteruses, ${ }^{19,20}$ and still others referred to application of the technique to all aetiologies. ${ }^{4,21}$ Apart from compressing the uterine body in uterine atony, the original paper on the B-Lynch suture also advocated its use for placenta praevia. It was proposed that the sutures would exert longitudinal compression and achieve evenly distributed tension over the uterus, including the lower segment. ${ }^{25}$ In addition, for cases of major placenta praevia, B-Lynch also described the use of additional independent figure-of-eight sutures placed either anteriorly, posteriorly, or both on the lower segment prior to suture application. ${ }^{4}$ Our results from this series confirm the effectiveness of the B-Lynch suture for patients with uterine atony and placenta praevia.

Very high success rates with compression sutures, usually in the range of $90 \%$ to $100 \%$, have been reported since the first paper by B-Lynch in 1997. ${ }^{4}$ However, many of these reports had very small sample sizes (single case reports or cohorts of $15-20$ patients) ${ }^{13,26}$ In recent years, larger case series started to be reported. One of the largest published series described experience from India, and reported a success rate of $94 \%$ ( 45 out of 48 patients) using Hayman sutures for PPH due to uterine atony. ${ }^{19}$ That series did not include cases with placenta praevia/ accreta. ${ }^{19}$ Another interesting case series consisted of a single surgeon's experience in Argentina over a 20-year period, and involved 539 cases of excessive obstetric bleeding from a variety of causes, including uterine atony, placenta praevia/accreta, cervical scar pregnancies as well as uterine/vaginal/cervical tears. ${ }^{21}$ Various surgical methods (often in combination) were utilised to treat these cases, and the overall success rate in those having the B-Lynch suture was $94 \%$ (81/86), while for Hayman sutures, Cho sutures, and Pereira sutures, the rates were $92 \%(34 / 37), 100 \%$ (37/37), and $100 \%(11 / 11)$, respectively. ${ }^{21}$ The very high success rates reported in this personal series could be ascribed to excellent surgical skills, optimal patient selection, and choice of procedures by a super-specialist, but may be difficult to reproduce elsewhere.

An earlier systematic review published in 2007 reported a success rate for uterine compression sutures ranging from $68 \%$ to $100 \%$ with an overall success rate of $92 \% .{ }^{6}$ Another review in 2010 compared success rates of $95 \%$ to $100 \%$ with eight different types of compression sutures. ${ }^{27}$ However, both reviews were based on case series with relatively small patient numbers, which might indicate a reporting bias and probably exaggerated the proportions with positive outcomes. Interestingly, another review published in 2010 that focused on the long-term complications of compression sutures and attempted to sum outcomes with B-Lynch sutures from 32 separate case series. ${ }^{23}$ This reported an overall hysterectomy (failure) rate of $70 / 174(40 \%)$, which was higher than most individual case series. ${ }^{23}$

In this series, the mode of delivery was vaginal in only one case (3\%), the rest being delivered by caesarean section (97\%). This was likely due to a bias in case selection in our practice. In patients with severe PPH not delivered by caesarean section, compression sutures were probably not the firstchoice surgical treatment due to consideration for laparotomy and opening a hysterotomy wound. Apparently, methods such as balloon tamponade ${ }^{28}$ were more common and convenient. The original intrauterine Bakri balloon was designed to control bleeding in patients with PPH caused by low-lying placenta praevia/accreta. ${ }^{29}$ It could be inserted easily and rapidly, without the need for laparotomy, and under minimal anaesthesia. It can also be used as a 'tamponade test' to aid decisions regarding proceeding to laparotomy. ${ }^{3}$ Of the 27 cases of severe PPH with balloon tamponade as the first- or secondline procedure within our review period (Fig), 10 
(37\%) had vaginal delivery. Our experience with the use of balloon tamponade has recently been published in another case series. ${ }^{30}$

We were unable to identify any reliable factors that would predict the success or failure of compression sutures in this case series, possibly due to the small size of our sample. Nor could we offer any coherent hypothesis to explain our lower success rate compared with that reported in the literature. As an obstetric specialist is available on-site in our hospital 24 hours a day, specialist involvement was initiated promptly in the management of all our cases. The 35 compression suture procedures were performed by a total of eight surgeons with very similar training and experiences in compression suture techniques. They all used a relatively standard technique with standard suture materials, and with standard anaesthetic and transfusion support in accordance with our hospital protocol. As compression sutures placed for prophylactic purposes were not included in this cohort, and all sutures were applied only in the presence of severe $\mathrm{PPH}$, the unselected nature of our cases could have contributed to the lower success rate. We believe that a success rate of around $70 \%$ would likely reflect the practical experience in a general regional obstetric training unit locally.

Major complications of B-Lynch and other compression sutures have been repeatedly described in the literature. Cases of uterine necrosis presenting several weeks post-delivery finally culminating in total or subtotal hysterectomy have been reported. ${ }^{31,32}$ Uterine necrosis was apparently the result of ischaemia produced by compression sutures. Haematometra might present with amenorrhoea ${ }^{33}$ and pyometria coupled with abdominal pain and fever, weeks or months postpartum. ${ }^{34}$ The occurrence of uterine cavity synechiae causing uterine outflow obstruction has also been reported after compression sutures, though infrequently. ${ }^{35}$ The combination of compression sutures and additional vessel ligation appeared more likely to cause complications such as ischaemia and inflammation, but so far no deaths have been reported in association with compression sutures. ${ }^{23}$

Apart from compression suture and balloon tamponade techniques, various fertility-preserving methods had been employed for patients with PPH, including pelvic devascularisation and radiological arterial embolisation. Pelvic devascularisation includes ligation of uterine artery and internal iliac artery, but such techniques require surgical expertise to apply and may be time-consuming. Complications such as broad-ligament haematoma, peripheral nerve ischaemia, and inadvertent ligation of the lower limb arteries have been reported. ${ }^{36,37}$ Radiological embolisation of the uterine artery warrants facilities and expertise in interventional radiology, which may not be readily available in some obstetric units. In addition, in cases of massive ongoing PPH, it may be difficult to transfer patients to such radiological facilities. Infrequently, complications such as ischaemia of the bladder and uterus have also been reported. ${ }^{38}$ A systematic review estimated a success (avoidance of hysterectomy) rate of around 92\% with uterine compression sutures, 91\% after arterial embolisation, 84\% after balloon tamponade, and $85 \%$ after iliac artery ligation or uterine devascularisation. ${ }^{6}$ Randomised controlled trials of these treatment options would be difficult to perform in such life-threatening emergencies. To date, there is no good evidence to suggest that one method is superior to another. As illustrated in several of the cases in our series, the sequential or concomitant use of these different interventions may help to increase the success rate. The patient's condition, cause of the PPH, expertise of the surgeon, and facilities available should all be considered when choosing the most suitable treatment option.

\section{Conclusion}

In our experience, the use of compression sutures for the management of massive $\mathrm{PPH}$ was effective in preventing hysterectomy in around two thirds of the cases. In this unselected cohort of patients with severe PPH, our success rate appeared to be lower than that reported in the literature. Other contingent protocols should be available, should compression sutures fail to control the haemorrhage. The combined or sequential use of compression sutures with other treatment modalities, such as balloon tamponade, pelvic devascularisation or radiological embolisation, may help to increase the success rate, and should be explored further.

\section{References}

1. American College of Obstetricians and Gynecologists. ACOG Practice Bulletin. Clinical Management Guidelines for Obstetricians-Gynecologists. Number 76, October 2006: postpartum hemorrhage. Obstet Gynecol 2006;108:1039-47.

2. Chandraharan E, Arulkumaran S. Surgical aspects of postpartum haemorrhage. Best Pract Res Clin Obstet Gynaecol 2008;22:1089-102.

3. Condous GS, Arulkumaran S. Medical and conservative surgical management of postpartum hemorrhage. J Obstet Gynaecol Can 2003;25:931-6.

4. B-Lynch C, Coker A, Lawal AH, Abu J, Cowen MJ. The B-Lynch surgical technique for the control of massive postpartum haemorrhage: an alternative to hysterectomy? Five cases reported. Br J Obstet Gynaecol 1997;104:372-5.

5. Hayman RG, Arulkumaran S, Steer PJ. Uterine compression sutures: surgical management of postpartum hemorrhage. Obstet Gynecol 2002;99:502-6.

6. Doumouchtsis SK, Papageorghiou AT, Arulkumaran S. Systematic review of conservative management of postpartum hemorrhage: what to do when medical treatment fails. Obstet Gynecol Surv 2007;62:540-7. 
7. Royal College of Obstetricians and Gynaecologists. RCOG Green-top guideline No 52. Prevention and management of postpartum haemorrhage; May 2009.

8. Varatharajan L, Chandraharan E, Sutton J, Lowe V, Arulkumaran S. Outcome of management of massive postpartum haemorrhage using the algorithm “HEMOSTASIS”. Int J Gynecol Obstet 2011;113:152-4.

9. Knight M; UKOSS. Peripartum hysterectomy in the UK: management and outcomes of the associated haemorrhage. BJOG 2007;114:1380-7.

10. Allam MS, B-Lynch C. The B-Lynch and other uterine compression suture techniques. Int J Gynaecol Obstet 2005;89:236-41.

11. Arduini M, Epicoco G, Clerici G, Bottaccioli E, Arena S, Affronti G. B-Lynch suture, intrauterine balloon, and endouterine hemostatic suture for the management of postpartum hemorrhage due to placenta previa accreta. Int J Gynaecol Obstet 2010;108:191-3.

12. Ghezzi F, Cromi A, Uccella S, Raio L, Bolis P, Surbek D. The Hayman technique: a simple method to treat postpartum haemorrhage. BJOG 2007;114:362-5.

13. Cho JH, Jun HS, Lee CN. Hemostatic suturing technique for uterine bleeding during cesarean delivery. Obstet Gynecol 2000;96:129-31.

14. Hwu YM, Chen CP, Chen HS, Su TH. Parallel vertica compression sutures: a technique to control bleeding from placenta praevia or accreta during caesarean section. BJOG 2005;112:1420-3.

15. Bhal K, Bhal N. Mulik V, Shankar L. The uterine compression suture-a valuable approach to control major haemorrhage at lower segment caesarean section. J Obstet Gynaecol 2005;25:10-4.

16. Nelson WL, O'Brien JM. The uterine sandwich for persistent uterine atony: combining the B-Lynch compression suture and an intrauterine Bakri balloon. Am J Obstet Gynecol 2007;196:e9-10.

17. Pereira A, Nunes F, Pedroso S, Saraiva J, Retto H, Meirinho M. Compressive uterine sutures to treat postpartum bleeding secondary to uterine atony. Obstet Gynecol 2005;106:569-72.

18. Shazly SA, Badee AY, Ali MK. The use of multiple 8 compression suturing as a novel procedure to preserve fertility in patients with placenta accreta: case series. Aust NZ J Obstet Gynaecol 2012;52:395-9.

19. Nanda S, Singhal SR. Hayman uterine compression stitch for arresting atonic postpartum hemorrhage: 5 years experience. Taiwan J Obstet Gynecol 2011;50:179-81.

20. Zheng J, Xiong X, Ma Q, Zhang X, Li M. A new uterine compression suture for postpartum haemorrhage with atony. BJOG 2011;118:370-4.

21. Palacios-Jaraquemada JM. Efficacy of surgical techniques to control obstetric haemorrhage: analysis of 539 cases. Acta Obstet Gynecol Scand 2011;90:1036-42.

22. Schnarwyler B, Passweg D, von Castelberg B. Successful treatment of drug refractory uterine atony by fundal compression sutures [in German]. Geburtshilfe Frauenheilkd 1996;56:151-3.

23. Fotopoulou C, Dudenhausen JW. Uterine compression sutures for preserving fertility in severe postpartum haemorrhage: an overview 13 years after the first description. J Obstet Gynaecol 2010;30:339-49.

24. Makino S, Tanaka T, Yorifuji T, Koshiishi T, Sugimura M, Takeda S. Double vertical compression sutures: a novel conservative approach to managing post-partum haemorrhage due to placenta praevia and atonic bleeding. Aust NZ J Obstet Gynaecol 2012;52:290-2.

25. B-Lynch C. Partial ischemic necrosis of the uterus following a uterine brace compression suture. BJOG 2005;112:126-7.

26. Quahba J, Piketty M, Huel C, et al. Uterine compression sutures for postpartum bleeding with uterine atony. BJOG 2007;114:619-22.

27. Mallappa Saroja CS, Nankani A, El-Hamamy E. Uterine compression sutures, an update: review of efficacy, safety and complications of B-Lynch suture and other uterine compression techniques for postpartum haemorrhage. Arch Gynecol Obstet 2010;281:581-8.

28. Georgiou C. Balloon tamponade in the management of postpartum haemorrhage: a review. BJOG 2009;116:748-57.

29. Bakri YN, Amri A, Abdul Jabbar F. Tamponade-balloon for obstetrical bleeding. Int J Gynaecol Obstet 2001;74:13942.

30. Kong MC, To WW. Balloon tamponade for postpartum haemorrhage: case series and literature review. Hong Kong Med J 2013;19:484-90.

31. Treloar EJ, Anderson RS, Andrews HS, Bailey JL. Uterine necrosis following B-Lynch suture for primary postpartum haemorrhage. BJOG 2006;113:486-8.

32. Joshi VM, Shrivastava M. Partial ischemic necrosis of the uterus following a uterine brace compression suture. BJOG 2004;111:279-80.

33. Dadhwal V, Sumana G, Mittal S. Hematometra following uterine compression sutures. Int J Gynaecol Obstet 2007;99:255-6.

34. Ochoa M, Allaire AD, Stitely ML. Pyometria after hemostatic square suture technique. Obstet Gynecol 2002;99:506-9.

35. Wu HH, Yeh GP. Uterine cavity synechiae after hemostatic square suturing technique. Obstet Gynecol 2005;105:11768.

36. O'Leary JA. Uterine artery ligation in the control of postcesarean hemorrhage. J Reprod Med 1995;40:189-93.

37. Shin RK, Stecker MM, Imbesi SG. Peripheral nerve ischaemia after internal iliac artery ligation. J Neurol Neurosurg Psychiatry 2001;70:411-2.

38. Porcu G, Roger V, Jacquier A, et al. Uterus and bladder necrosis after uterine artery embolisation for postpartum haemorrhage. BJOG 2005;112:122-3. 